\title{
I. Vorbemerkung
}

Obwohl eine Vielzahl von Arbeiten zum islamischen Recht vorliegen, wurde bisher selten versucht, die islamischen Rechtswerke auf ihren möglichen Gehalt als Quelle historischer Information zu iberprifen. Auch wurde vielfach eine Art Querschnitt des islamischen Rechts vorgestellt, der von möglichen Einflüssen lokaler Bedingungen auf die materielle Seite des Rechts absah. Im wesentlichen in Hinsicht auf diese beiden Fragen sollen in dieser Arbeit Werke der mālikitischen Rechtsschule untersucht werden.

Für die Möglichkeit, diese Arbeit zu verfassen, bin ich verschiedenen Seiten zu Dank verpflichtet.

In erster Linie gilt mein Dank meinem akademischen Lehrer und Doktorvater, Herrn Prof. Dr. Tilman Nagel, der stets bereit war, mich mit vielen Hinweisen und Ratschlägen zu unterstuitzen.

Ebenfalls danke ich meinem akademischen Lehrer, Herrn Prof. Dr. Peter Bachmann, für seine große Hilfsbereitschaft bei auftretenden Fragen.

Besonders gilt mein Dank auch der Studienstiftung des deutschen Volkes, die es mir durch ein Stipendium ermöglichte, diese Arbeit zu verfassen. 
